\title{
ETHICAL RESPONSIBILITIES OF INSTRUCTORS IN TESTING COURSES ${ }^{1}$
}

\author{
EDWARD S. BORDIN \\ University of Michigan
}

THE purpose of this paper is to examine the "Proposed Statement of Ethical Standards for the Distribution of Psychological Tests and Diagnostic Aids"' from the point of view of instructors of courses in psychological testing. The aim is to clarify and emphasize what procedures are encouraged, discouraged or questioned by the proposed code.

The statement suggests four principles which bear directly upon procedures in testing courses. These are as follows:

I. Courses in the uses of psychological tests should admit only students who have the supporting training required for the use of the types of tests being studied.

2. Test materials should be retained by students only if they are graduate students in fields in which tests are professional equipment, and if they have the professional maturity which suggests that they will use tests properly and protect them from abuse by others.

3. Instructors of courses which require the taking or the administration of tests by students for didactic purposes should protect the examinees by insuring that the tests and the test results are used in a professional manner, and should also provide facilities for the counseling of those who are tested if they are emotionally disturbed as a result of this testing.

4. Tests scores like test materials should be released only to persons who are qualified to interpret them and not indiscriminately or for some evaluation. 'Self appraisal' units in school or college courses should be closely supervised by qualified psychologists or counselors with adequate provisions for the referral and counseling of individuals when needed. ${ }^{3}$

In order to make clear the implications of these principles, particularly the last two, it would seem desirable to spell out

1 Presented as part of a symposium on "A Code for the Distribution of Psycho-

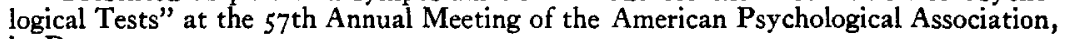
in Denver, 1949.

${ }^{2}$ See American Psychologist, IV (1949), 495-501.

${ }^{3}$ Ibid, pp. $498-499$. 
the assumptions which lie behind them. First and foremost, psychologists assume that psychological tests have potentialities for harming individuals as well as helping them, depending upon the professional adequacy of the test user. This assumption is basic to the whole idea of ethical standards for the use of tests. In analyzing the potential for harm in psychological tests, we shall focus particularly on the counseling and clinical aspects of the tests.

The danger points for individuals exposed to psychological tests might be listed as follows:

I. The process of taking the test: Any test, particularly any projective test, by virtue of the fact that it touches the core of the individual's personality, has potentialities for disturbing the subject simply by testing him. It is often mistakenly assumed that only projective tests have this property. It has been my experience that pencil-and-paper tests like the Minnesota Multiphasic can create considerable anxiety in the subject. As tests touch aspects of the individual's personality further removed from the core of the motivational structure, their normal disturbing properties decrease. On the average, the exposure to an intelligence test is more disturbing than exposure to a spatial relations test, etc.

2. The interpretation of test results: Inaccurate interpretations of psychological tests have potentialities of harm. Test manuals do not in themselves provide a sufficient basis for accurate interpretations of even the least complex psychological instrument. At a minimum, the interpretation of psychological tests involves a knowledge of general concepts of measurement as well as considerable knowledge of specific relations among various traits.

3. The point of integration of the test interpretations: While the dangers of inaccurate interpretations of tests are readily seen by all, many seem to overlook the fact that the danger is not past when one does give an accurate interpretation. It is still necessary for the other person to be able to integrate this interpretation into his self percept. Where considerable anxiety is generated, sensitive clinical skills will be necessary to help the subject work through this anxiety.

Let us now consider how these assumptions apply to com- 
mon practices in courses dealing with tests. One of the ways of familiarizing students with tests is to have them take the tests, score them, and make up profile sheets for themselves. It should be evident that their status as students in the courses does not provide them with the background for individualized interpretation. In any case, the problem of proper integration and assimilation of the test interpretations would remain. It would appear necessary to make some sort of provisions for interviews with students in the course for the purpose of reviewing their interpretations of their own test scores and aiding them to overcome any failures to integrate these findings. Anyone who has had experience in a college counseling service can report on numerous instances of misinterpretations as well as failures to integrate results of tests taken under the above conditions. One example will suffice. This is an instance where a student had taken a scientific aptitude test which was heavily loaded with achievement items. The test and norms were designed for high-school students. Since the student had taken several science courses to meet his general graduation requirements, he was able to score quite high in terms of norms for high-school graduates. Although he had made a definite choice of business administration, he was thrown into a state of indecision by this test result, partly because his father was a successful engineer. Later counseling proved that his original choice was well founded and that his indecision would have been short lived if the tests had been properly interpreted to him by someone who could also have helped him to relate these results to his percept of himself as different from his father.

Another common practice in courses dealing with individual tests is to have the student administer the test in question to a given number of subjects. Often he obtains these subjects wherever he can, among his family, friends, or even chance acquaintances. In this type of situation, all three of the dangers listed above are involved. One particular instance serves to high-light these dangers. A student in a class in projective techniques administered the Rorschach to a man and wife who were neighbors. Both of them became noticeably anxious as a result of taking the test. Although the student had not intended 
to interpret the test results to them he could not withstand their pressure for interpretation. He felt that their anxiety was so great that he had to give them some kind of interpretation. Even though he tried to keep his interpretations to a minimum, he soon found the man and wife trying to involve him in their personal problems. Fortunately, this is a story with a happy ending because this student was mature enough and had been sufficiently primed on such problems to be able to quickly call a halt, and to point out to the couple what they were doing and then to suggest to them available community resources for dealing with their problem. It seems clear that in courses dealing with individual tests considerable time must be devoted to clarifying for the students the restrictions involved in their roles as testers and also in aiding them to develop the skills which will enable them to stay within those roles. With all this, the need for extremely close supervision of all of their testing activities seems axiomatic.

In passing, it would appear that one of the important responsibilities of the instructor in the course in testing is to sensitize the student to the responsibilities for human welfare that are involved in the use of psychological tests. Reviewing with them statements like those proposed by the sub-committee on test distribution would help to accomplish this end.

One of the most important contributions of the instructor can be in the direction of forcing authors and distributors of tests to maintain standards in the preparation of tests for distribution. One of the reasons that there exist persons who are willing to release tests before they have been properly standardized and validated is that they can be sold without the more expensive processing necessary. While some of this market arises from the distribution of tests to unqualified users, unfortunately a substantial portion of the market is made up of people with professional training. Instructors should place high priority on the objective of developing a critical ability which will diminish the market for these untried and unproved products. From the long view, instructors in testing courses have a highly significant contribution to make to the protection of public interest where the use of psychological tests and diagnostic aids is concerned. 